\title{
Invasive pulmonary aspergillosis in a COVID-19 recovered patient: unravelling an infective sequalae of the SARS-CoV-2 virus
}

\author{
Benhur Joel Shadrach ${ }^{1}$, Rishabh Goel ${ }^{2}$, Kunal Deokar ${ }^{1}$, Anukool Jain ${ }^{3}$ \\ ${ }^{1}$ Department of Pulmonary Medicine, All India Institute of Medical Sciences (AIIMS), Jodhpur; ${ }^{2}$ Department of \\ Pulmonary Medicine, Shahi Global Hospital, Gorakhpur; ${ }^{3}$ Department of Pulmonary Medicine, Pushpanjali Hospital, \\ Agra, India
}

\section{Dear Editor,}

A 55-year-female, house wife, non-smoker, morbidly obese $(\mathrm{BMI}>35)$ with no other co-morbidities or pre-existing lung disease presented to the emergency room with complaints of highgrade fever, cough with minimal sputum, progressive breathlessness, streaky haemoptysis, and anorexia for the past 5 days. She was admitted in intensive care unit (ICU) for severe COVID-19 pneumonia three months back and had successfully recovered after 24 days of hospitalization. She had received broad-spectrum intravenous antibiotics, antivirals (initially favipiravir then switched to remdesivir), corticosteroids (dexamethasone $6 \mathrm{mg} \mathrm{I.V}$ OD), anticoagulation (low molecular weight heparin) and other supportive treatment for COVID-19 pneumonia. After recovery, her medications were discontinued and she was discharged to home on short-term oxygen therapy for residual dyspnoea and

Correspondence: Rishabh Goel, Department of Pulmonary Medicine, Shahi Global Hospital, Gorakhpur, Uttar Pradesh, 273001, India. Tel.+91.9305259403. E-mail: rishabhgoel1905@gmail.com

Authors' contribution: All the authors made a substantive intellectual contribution. BJS, RG, guarantors. All the authors have read and approved the final version of the manuscript and agreed to be accountable for all aspects of the work.

Conflict of interest: The authors declare that they have no competing interests, and all authors confirm accuracy.

Informed consent: Written informed consent was obtained from the patient to publish her clinical details and investigations. The patient understands that her name and initials will not be published but anonymity cannot be guaranteed.

Key words: IPA; COVID-19; CAPA; infective sequelae; bronchoalveolar lavage.

Received for publication: 30 October 2020.

Accepted for publication: 29 January 2021.

${ }^{\circ}$ Copyright: the Author(s), 2021

Licensee PAGEPress, Italy

Monaldi Archives for Chest Disease 2021; 91:1664

doi: 10.4081/monaldi.2021.1664

This article is distributed under the terms of the Creative Commons Attribution Noncommercial License (by-nc 4.0) which permits any noncommercial use, distribution, and reproduction in any medium, provided the original author(s) and source are credited. hypoxemia $\left(\mathrm{PaO}_{2}-53.5\right.$ on room air). However, she had multiple hospitalizations for worsening dyspnoea and had received pulse corticosteroid therapy in the next 2 months. On present admission, there was tachycardia, tachypnoea, severe respiratory distress and reduced peripheral oxygen saturation $\left(\mathrm{SpO}_{2}-74 \%\right)$ on room air. Arterial blood gas revealed acute respiratory alkalosis and hypoxemic respiratory failure. On chest auscultation, bilateral basal inspiratory crepitations were heard. In view of worsening hypoxemia, she was intubated and put on controlled mechanical ventilation. Chest radiograph showed bilateral fine interstitial shadows and haziness in left lower lung fields. Reverse transcriptase-polymerase chain reaction (RT-PCR) of nasopharyngeal swab was negative for COVID-19 and endotracheal aspirate for microbiological cultures were non-contributory. High resolution computerized tomography (HRCT) of the thorax disclosed bilateral mid and lower zone ground glass opacities with superimposed septal thickening, consolidation in left lower lobe and discrete pulmonary nodules (Figure 1). Bronchoscopy and bronchoalveolar lavage (BAL) were performed to rule out infectious cause. BAL cytology and microbiology was negative for tuberculosis and bacterial infections. However, BAL fluid fungal stain revealed acute angled branching septate hyphae with narrow base and fungal culture grew Aspergillus fumigatus. Serum and BAL galactomannan (GM) levels were significantly raised with GM index of 1.2 and 4.7 of serum and BAL fluid respectively. She was labelled as a case of COVID-19 associated invasive pulmonary aspergillosis (CAPA) and initiated on intravenous voriconazole therapy. There was a dramatic response to antifungal therapy and she was she was successfully weaned off from mechanical ventilation after 10 days. Finally, after 21 days of hospitalization, she was discharged on antifungals in a hemodynamically stable condition with advice to follow up in OPD and a repeat CT thorax planned after 6-8 weeks of voriconazole therapy.

Pulmonary aspergillosis encompasses a plethora of clinical syndromes predominantly caused by the ubiquitous mould A. fumigatus, depending on the host immune response and pulmonary structural abnormalities [1]. IPA, a severe form of aspergillosis, usually occurs in immunodeficiency states but also have been found to occur in critically-ill immunocompetent patients [2]. Influenza infection can independently predispose to IPA referred to as influenza associated pulmonary aspergillosis (IAPA), occurring in severe influenza related pneumonia and acute respiratory distress syndrome [3]. COVID-19 pneumonia shares similar clinical features with influenza infection and akin to IAPA, "COVID-19 associated pulmonary aspergillosis" (CAPA) have been reported recently in hospitalized patients with severe COVID-19 in the ICUs [4-7] (Table 1). Various mechanisms which have been proposed to predispose to CAPA include exuber- 
Table 1. Demographic and clinical characteristics of CAPA patients and their outcomes.

\begin{tabular}{|c|c|c|c|c|c|c|}
\hline Author & $\begin{array}{c}\text { Age in years } \\
\text { and sex }\end{array}$ & Co-morbidities & $\begin{array}{l}\text { EORTC/MSG } \\
\text { risk factors }\end{array}$ & $\begin{array}{l}\text { Microbiological } \\
\text { diagnosis of CAPA }\end{array}$ & $\begin{array}{l}\text { Antifungal } \\
\text { treatment }\end{array}$ & Outcome \\
\hline Prates et al. [4] & $70, \mathrm{M}$ & COPD, DM, OSA & Absent & ETA culture & Voriconazole & Death \\
\hline Helleberg et al. [5] & $\begin{array}{c}2 \text { patients } \\
63, \mathrm{~F} \\
53, \mathrm{~F}\end{array}$ & HTN, BA & Absent & $\begin{array}{c}\text { ETA culture, } \\
\text { BAL and serum GM }\end{array}$ & Voriconazole & Death-2 \\
\hline Arkel et al. [6] & $\begin{array}{c}6 \text { patients } \\
\text { Median age-64, } \\
\text { all were males }\end{array}$ & $\begin{array}{l}\text { DM, BA, COPD } \\
\text { Cardiomyopathy }\end{array}$ & absent & $\begin{array}{l}\text { BAL culture and } \\
\text { BAL GM-3 } \\
\text { ETA culture-2 } \\
\text { Sputum culture-1 }\end{array}$ & $\begin{array}{l}\text { Voriconazole and } \\
\text { Anidulafungin-5 } \\
\text { Liposomal AMB-1 }\end{array}$ & $\begin{array}{c}\text { Death-4 } \\
\text { Recovery-2 }\end{array}$ \\
\hline Rutsaert et al. [7] & $\begin{array}{c}7 \text { patients } \\
\text { Median age-66, } \\
\text { all were males }\end{array}$ & $\begin{array}{l}\text { DM, HTN, OSA, } \\
\text { Obesity, hyperlipidaemia, } \\
\text { HIV, CKD, AML, IPA, } \\
\text { Pemphigus }\end{array}$ & Present in 2 cases & $\begin{array}{l}\text { Histology-4 } \\
\text { BAL-1 } \\
\text { ETA culture-1 }\end{array}$ & $\begin{array}{l}\text { Voriconazole-4 } \\
\text { Isavuconazole- } 2\end{array}$ & $\begin{array}{l}\text { Recovery-3 } \\
\text { Death-4 }\end{array}$ \\
\hline Present case & $55, \mathrm{~F}$ & Obesity & Absent & $\begin{array}{c}\text { BAL culture, } \\
\text { BAL and serum GM }\end{array}$ & Voriconazole & Recovery \\
\hline
\end{tabular}

DM, diabetes mellitus; HTN, hypertension; OSA, obstructive sleep apnoea; AML, acute myeloid leukaemia; HIV, human immunodeficiency virus; BA, bronchial asthma; COPD, chronic obstructive pulmonary disease; CKD, chronic kidney disease; EORTC/MSG, European organization for research and treatment of cancer and mycosis study group; AMB, amphotericin B; ETA, endotracheal aspirate.

ant inflammation, influenza co-infection, activated IL-1 pathway and the use of corticosteroids, and immunomodulators including IL-6 (tocilizumab) and IL-1 inhibitors (anakinra) [8]. Typical radiological findings of IPA including nodules, halo sign, air crescent sign and cavitation are less common in CAPA, although not mandatory for diagnosis, if present, can possibly reduce the burden of over-reliance on laboratory mycological parameters. Histology is gold standard in diagnosis of IPA and in its absence, a diagnostic algorithm is given by Armstrong et al, classifying patients into CAPA high likely, CAPA likely, CAPA unlikely, and CAPA not excluded on the basis of bronchoalveolar lavage (BAL) fluid aspergillus biomarkers/culture and serum biomarkers (aspergillus antigen, PCR, galactomannan, and beta-D-glucan) [9]. A high likely CAPA requires a combination of atleast single BAL biomarker/culture positivity and serum biomarker positivity, war-

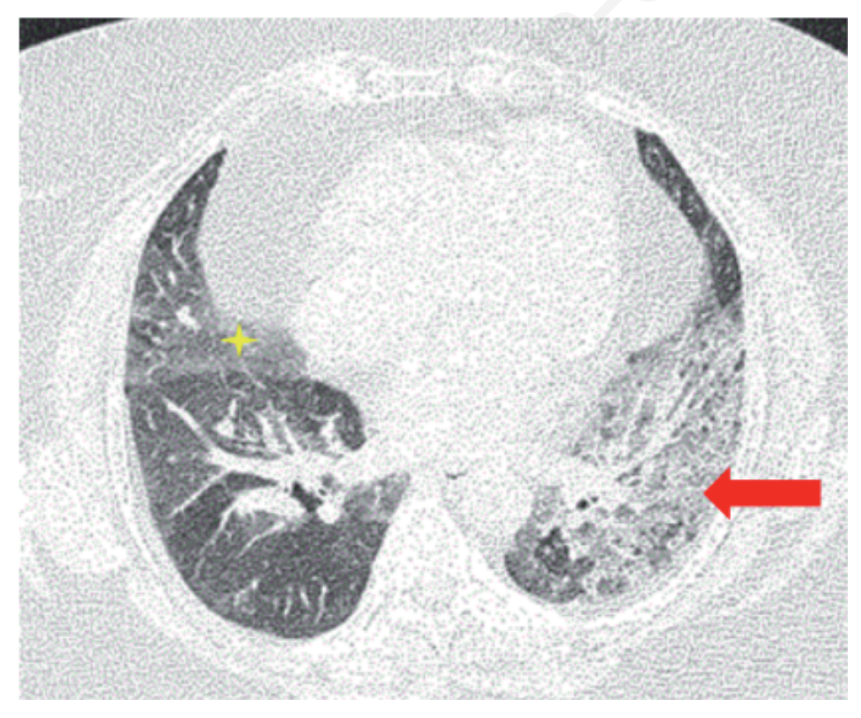

Figure 1. HRCT thorax axial reformatted images at the level of inferior pulmonary vein shows patchy ground glass opacities (yellow asterix) in bilateral lung fields and a left lower lobe consolidation (red arrow) and a few ill-defined centrilobular nodules. ranting systemic antifungal therapy, whereas antifungals ought to be considered in CAPA likely and CAPA not excluded groups if risk factors for CAPA/IPA exist or in case of clinico-radiological worsening [9]. BAL GM has been found to be more sensitive than its serum counterpart in the diagnosis of CAPA and BAL GM $>1$ is indicative of CAPA. Management includes systemic antifungals with Voriconazole being the drug of choice and Amphotericin-B reserved for salvage therapy either as monotherapy or in combination with echinocandins and isavuconazole/posaconazole [10]. Although, aspergillus co-infection in severe COVID-19 have been extensively described in the literature, to the best of our knowledge, we believe our report is the first to have highlighted IPA as a post COVID-19 infective sequalae. Apart from CAPA, other differential diagnosis for acute respiratory worsening with abnormal thoracic radiology in a post COVID-19 patient include acute pulmonary thromboembolism, diffuse lung disease/interstitial lung disease, re-infection with SARS-CoV-2 virus, superadded bacterial pneumonia, and other invasive fungal infections. An integrated multimodality approach involving team of pulmonologists, intensivists, microbiologists and infectious disease experts may be required in CAPA diagnosis and management.

Our report unravels an uncommon yet life-threatening association of IPA in a COVID-19 recovered patient, possibly adding to the addendum of evolving list of complications of the COVID-19 sequalae. It further raises awareness among clinicians to evaluate for IPA in especially in severe symptomatic post-viral pneumonia patients as there is a paucity of typical clinico-radiological findings in these cases and timely intervention is paramount in reducing morbidity and mortality.

\section{References}

1. Franquet T, Müller NL, Giménez A, et al. Spectrum of pulmonary aspergillosis: histologic, clinical, and radiologic findings. Radiographics 2001;21:825-37.

2. Kousha M, Tadi R, Soubani AO. Pulmonary aspergillosis: a clinical review. Eur Respir Rev 2011;20:156-74.

3. Schauwvlieghe AFAD, Rijnders BJA, Philips N, et al. Invasive 
aspergillosis in patients admitted to the intensive care unit with severe influenza: a retrospective cohort study. Lancet Respir Med 2018;6:782-92.

4. Prattes J, Valentin T, Hoenigl M, et al. Invasive pulmonary aspergillosis complicating COVID-19 in the ICU - A case report. Med Mycol Case Rep 2020;31:2-5.

5. Helleberg M, Steensen M, Arendrup MC. Invasive aspergillosis in patients with severe COVID-19 pneumonia. Clin Microbiol Infect 2020;27:147-8.

6. van Arkel ALE, Rijpstra TA, Belderbos HNA, et al. COVID19-associated pulmonary aspergillosis. Am J Respir Crit Care Med 2020;202:132-5.

7. Rutsaert L, Steinfort N, Van Hunsel T, et al. COVID-19-asso- ciated invasive pulmonary aspergillosis. Ann Intensive Care 2020;10:71.

8. Arastehfar A, Carvalho A, van de Veerdonk FL, et al. COVID19 associated pulmonary aspergillosis (CAPA) - From immunology to treatment. J Fungi (Basel) 2020;6:91.

9. Armstrong-James D, Youngs J, Bicanic T, et al. Confronting and mitigating the risk of COVID-19 associated pulmonary aspergillosis. Eur Respir J 2020;56:2002554.

10. Patterson TF, Thompson GR 3rd, Denning DW, et al. practice guidelines for the diagnosis and management of aspergillosis: 2016 Update by the Infectious Diseases Society of America. Clin Infect Dis 2016;63:e1-e60. 